\title{
Measuring the impact of international $R \& D$ cooperation: the case of Spanish firms participating in the EU Framework Programme
}

\author{
Ascension Barajas $^{\mathrm{a}^{*}}$, Elena Huergo ${ }^{\mathrm{b}^{* *}}$ and Lourdes Moreno ${ }^{\mathrm{b}^{* *}}$ \\ ${ }^{a}$ Department of Impact Analysis, CDTI, Madrid, Spain; \\ ${ }^{\mathrm{b}}$ GRIPICO - Department of Economic Analysis, Universidad Complutense de Madrid, Spain
}

November 2009

\begin{abstract}
The objective of this paper is to analyse the effects of international R\&D cooperation on firms' economic performance. Our empirical analysis, based on Spanish firms' participation in the Framework Programme (FP) between 1995 and 2005, has confirmed that: (1) cooperation within the FP has a positive impact on the technological capacity of firms, captured through intangible fixed assets and (2) the technological capacity of firms is positively related to their economic performance, measured by labour productivity.
\end{abstract}

Keywords: international R\&D cooperation, Framework Programme, impact assessment

J.E.L. Classification: H81, L2, O3

The authors thank Luis Corchón and the audiences at the ASIGO Conference (Nuremberg) and the $36^{\text {th }}$ Conference of the EARIE (Ljubljana) for their helpful comments. All errors are ours. This research has been partially funded by the CICYT project SEJ2007-65520/ECON. Elena Huergo and Lourdes Moreno also acknowledge financial support from CDTI to develop this research.

An earlier Spanish version of this paper has been published as Working Paper No. 08. of CDTI, Dpto. de Estudios (http://www.cdti.es/recursos/publicaciones/archivos/27189_610610200912171.pdf).

* Corresponding author: CDTI (Centre for the Development of Industrial Technology). Dpto. de Estudios. Dirección de Promoción, Estudios y Servicios corporativos. C/Cid 4, 28001 Madrid. España. E-mail: abi@cdti.es

** GRIPICO (Group for Research in Productivity, Innovation and Competition). Dpto. Fundamentos del Análisis Económico I. Facultad de CC. Económicas y Empresariales. Universidad Complutense de Madrid. Campus de Somosaguas. 28223 Madrid. España. Tel.: +34 913942408. Fax: +34 913942561. E-mail: ehuergo@ccee.ucm.es 


\section{Introduction}

The objective of this paper is to analyse the effects of $R \& D$ cooperation, exploring the relationship between cooperation, knowledge generation and economic results. Empirical analysis is focused on consortia supported by the R\&D Framework Programme (FP) of the European Union and, more specifically, our sample refers to those Spanish firms participating during the period 1995-2005.

Consortia shaped under the FP have been considered in the literature to be a clear example of international R\&D cooperation, since they involve partners from different nationalities which invest their own resources in R\&D activities in order to obtain appropriable results. Prior studies concluded that the FP has contributed to building and consolidating R\&D networks within the European area (Roediger-Schluga and Barber, 2006; Breschi and Cusmano, 2006). Nevertheless, empirical evidence about the effect of the FP on firms' economic performance is scarce.

The main obstacles that authors must face when trying to measure the impact of participation in the FP are two: 1) how to avoid the self-selection effect and 2) how to join data on participation and on economic performance for a period long enough to capture the long-term effect of the FP R\&D projects.

Following Barajas and Huergo (2009), our empirical approach takes into account that cooperation in this program is the result of two decisions. First, firms have to decide whether or not they engage in the consortia. Second, the agency decides to approve or to reject the project after the evaluation. In this second stage, we are considering a selection equation in order to avoid the self-selection effect that can produce bias when the information considered refers only to firms with accepted projects. Afterwards, we analyse the effect of participating in the FP on technological and economic results.

The second obstacle has been solved by joining two complementary databases. The first one, provided by the CDTI (the public organism in charge of monitoring the participation of Spanish firms within the FP), contains much relevant information about the FP projects and the participants and allows us to discriminate between the decision to apply and the agency selection. Additionally, we use data provided by the SABI database that consists of 
company accounts for over 1,000,000 Spanish firms. This allows us to build a control sample with information on economic variables. Thus, we compile homogeneous samples containing information about more than 50,000 firms and for a long-term period.

In contrast to other impact studies of the FP, the features of our database allow us to carry out the empirical analysis from a more in-depth and precise approach. Previous literature on the economic impact of the FP has confirmed the positive effect on firms' technological capabilities, but has not provided evidence about any significant effect on economic performance. Our approach, based on the work by Crepón et al. (1998), believes that technological capabilities have a direct effect on productivity and thus participation in the FP could also have an indirect effect on this performance measure.

Moreover, our database contains information for a period long enough to capture the longterm impact of participation in FP consortia. Thus, we consider a time lag of five years from the application year of each project. Other works are not able to establish the same time lag for all the projects or consider a short-term horizon ${ }^{1}$. Finally, previous literature does not take into account the existing differences among FP instruments. In order to guarantee the homogeneity of the sample, only Specific Targeted Research Projects (STREPs) and Integrated Projects are considered in the present paper.

Following this introduction, Section 2 summarises prior literature focused on R\&D cooperation impact and, more specifically, on the FP. In Section 3, we present the database and the model used to carry out the empirical analysis contained in Section 4. Finally, in Section 5, we draw some conclusions from the results, also pointing out key policy implications.

\footnotetext{
${ }^{1}$ Benfratello and Sembenelli (2002) consider a sample of firms participating during the period 1992-1994, indistinctly, and analyse their economic results for the period 1995-1996. Dekker and Kleinknecht (2008) use information for firms supported in FP4 and FP5, but they have no information about the concrete year of participation. Impact is measured considering sales of new products introduced in the market during the period 2002-2004 for the whole sample.
} 


\section{Previous empirical evidence on the impact of $R \& D$ cooperation}

The origin of cooperation impact studies must be explained in the framework of the literature on R\&D impact. Following the seminal works by Solow (1957) and other authors which incorporated $R \& D$ as an endogenous factor in the production function (Romer, 1990; Grossman and Helpman, 1991), many studies have tried to quantify the contribution of technology to the economic growth of a country, industry branch or enterprise, concluding that the private return of $R \& D$ investments is lower than the social one. Griliches (1992), Mohnen (1996) and Nadiri (1993) confirmed that, on average, the social rate of return is $50 \%$ to $100 \%$ higher than the private one. Griliches and Mairesse (1984), Jaffe (1986) and Verspragen (1995) demonstrated that those spillover effects associated with $R \& D$ activities are responsible for the increasing rate of returns when knowledge flows from one firm or institution to others.

In the 1990s, available data on firms' innovative activities open new research paths and new approaches are proposed. One of the most relevant works is the paper by Crepon et al. (1998). Using data from the French Innovation Survey, these authors build a model (CDM model) which considers that the effect of $\mathrm{R} \& \mathrm{D}$ on firms' productivity is the result of the innovation outputs and not directly of the R\&D activity. Their empirical analysis concludes that technological results are favoured by the R\&D intensity and the innovative dynamic of the activity branch. Moreover, productivity is positively influenced by the introduction of innovations in the market when controlling by human resources' qualification and physical capital.

The basic CDM model includes variables measuring the internal effort in $R \& D$, but does not take into account the effect of external spillovers. In this respect, cooperation has been considered by some authors a valid proxy for explaining knowledge generation associated with those knowledge spillovers. Cincera et al. (2003) argue that cooperation is an alternative for measuring voluntary access to external knowledge and also for controlling the involuntary outgoing spillovers. In fact, a considerable amount of empirical research corroborates the relationship between the propensity to cooperate and the relevance of spillovers for the innovation process. 
Cassiman and Veugelers (2002) find, for the case of Belgian firms, that cooperation seems to be a suitable strategy for internalising spillovers within formal consortia, since those firms which consider incoming spillovers to be more important have a greater probability of cooperating. Using data from the Community Innovation Survey and based on the previous work, several studies have been carried out, stressing the relevance of spillovers as an explanatory factor for $R \& D$ cooperation (Abramovsky et al. 2009). For the case of Spanish firms, López (2008) confirms that the probability of cooperating is positively influenced by the increasing relevance of incoming spillovers (measured as publicly available information useful for the firms' innovation activity) and by the higher effectiveness of the protection of intellectual property rights.

Previous literature analysing the effect of cooperation on firms' performance is characterised by the heterogeneity of models, due, in part, to the relative novelty of this research area. Most papers are focused on measuring the cooperation effect on innovation output and economic results. Moreover, some also explore the relationship between cooperation effects and the type of partner selected by the company.

One of the first studies analysing the effect of cooperation on economic results was carried out by Siebert (1996). This author uses a sample of 314 US joint research ventures registered from 1985 to 1992 in the NCRA-JRV databases (National Cooperative Research Act) and confirms that the effect of $R \& D$ intensity on profit margin is higher for cooperating firms than for non-cooperating firms. Nevertheless, cooperation does not affect profit margin.

Thanks to the improvement and international harmonisation of innovation statistics in the 1990s (mainly throughout the CIS initiative), researchers were able to measure the impact of $R \& D$ cooperation on new output indicators closer to the firms' innovative activity. This information source also allows for distinguishing different kinds of cooperation according to the type of organisation selected by the company to carry our joint $R \& D$ projects. Researchers introduce explanatory variables capturing the type of cooperation (related to the type of partner) in empirical models, and measure their impact on some innovation output indicators. Most of the papers find a positive relationship between cooperation with universities/research centers and innovation output measured by the volume of sales due to new products (Lööf and Heshmati, 2002; Faems et al., 2005; Lööf and Broströn, 2008). 
Nevertheless, due to the interest in knowing the real impact of cooperation on economic performance, and not only on innovation results, some authors try to go beyond carrying out more exhaustive research. One of the most cited papers is the study by Belderbos et al. (2004). These authors measure the effect of different types of cooperation on Dutch firms' performance, captured by two indicators: the growth of added value per employee (as an indicator of labour productivity) and the growth of sales per employee from new-to-themarket products (as an indicator of "innovative sales productivity"). Available data for the period 1996-1998 allow them to match information on innovative activity (from the CIS) and financial indicators for more than 2,000 enterprises. They cannot confirm that cooperation with universities has an effect on labour productivity, but instead find a significant impact on innovative sales growth. Aschhoff and Schmidt (2008) reinforce the positive relationship between cooperation with universities and the new-to-the-market product innovation. In the same study, these authors also confirm the effect of cooperation in process innovation, capturing throughout this indicator the cost-reduction factor associated with collaborative R\&D.

Another remarkable attempt to demonstrate the economic effects of $R \& D$ cooperation is the paper by Cincera et al. (2003). These authors analyse the effect of international R\&D cooperation by including not only $R \& D$ expenditure, but also $R \& D$ cooperation in a classical productive growth function. This latter indicator is a proxy of available external know-how (knowledge spillovers) and complements the internal innovation effort. Empirical results confirm the positive impact of R\&D intensity on sales growth. However, only cooperation with more applied objectives (with customers, suppliers or other companies) has a positive impact on sales growth.

In general, the literature confirms the existence of a positive relationship between $R \& D$ cooperation and innovative results, but the effect on economic performance is not so evident. Taking into account different types of cooperation processes, empirical evidence seems to corroborate that the more market-oriented the cooperation is, the higher the probability of finding positive economic effects (Benfratello and Sembenelli, 2002; Cincera et al., 2003; Belderbos et al., 2004). 


\section{The impact of cooperation taking place within the FP}

The Framework Programme (FP) is the main political instrument supporting cooperative R\&D within the European Union. It was born in 1984 with the aim of coordinating dispersed R\&D activities funded by the European Commission. Since then, seven editions of the FP have been launched, evolving towards increasing budgets, new participation models and wider research priorities.

Throughout the seven editions, the operative scheme of the FP has been characterised by several key aspects. Roediger-Schula and Barber (2006) remark that all projects are promoted by self-organised consortia, shaped by different kinds of partners and located in different nations (usually, consortia are integrated by firms, public research centres, universities and users). Moreover, supported projects have a limited duration and their R\&D activity is co-financed by grants coming from the European Commission and private funds coming from consortia partners. Evaluation and selection processes have been traditionally based on scientific excellence and relevant socio-economic aspects and carried out by independent experts in each technological area.

R\&D cooperation within the FP is characterised by some specific features, such as the participation of universities and research institutes in consortia and the relevance of precompetitive research. Thus, we can assume that FP projects are close to the public-private or institutional cooperation model. In fact, as we will show below, literature on FP impact remarks that the main contribution of this programme is the improvement of innovation capabilities and most of the empirical studies do not find a direct effect on economic results.

Impact studies carried out in several European countries (the UK, Austria, Finland, Germany, and Ireland) have reported the same general conclusions regarding firms' performance: low levels of commercialisation, significant generation of new scientific knowledge, significant acquisition of technical knowledge and capabilities; improved access to technical networks (DTI-Office of Science and Technology, 2004). In the same line, Georghiou et al. (1992) find that the main benefit for industry is the improvement of skills. Also Luukkonen (1998) observes that the promotion of 'infrastructural' matters 
(such as skills and training of personnel) can be considered the primary impact of EU research programmes.

The specifics of the FP regarding economic impact are reinforced by Benfratello and Sembenelli (2002). Matching data on 411 participants in Eureka and in the FP and balance sheet information from the AMADEUS database, these authors compare the effect of cooperation taking place in the two different programmes. They corroborate the positive influence of Eureka cooperation on some economic variables (labour productivity and price cost margins), but they cannot find any effect for the case of FP participants. Authors explain these results by the differences between the two programmes: Eureka is more market-oriented and the FP is more focused on pre-competitive projects.

Some studies have found different effects regarding firms' characteristics. Thus, Luukkonen (2000) suggests that commercial and short-term objectives are much more relevant for small firms, since these companies are not able to maintain a large project portfolio and their innovation activity is based on short return periods, allowing them to finance consecutive R\&D projects (European Commission, 2009). For the case of the Swedish industry, Arnold et al. (2008) report that the FP impact largely depends on the activity branch. They analyse four industries and confirm that, when the objectives of the FP consortia are closer to the market and the participation of big companies is more important, like in ICT or vehicles, the economic impact is higher. On the contrary, in live sciences or energy, the most relevant impact of the FP is related to the increasing technological capabilities of SMEs.

Similar results were obtained by Polt et al. (2008). They analyse the relationship between the participation in the FP and the innovative activity of enterprises using data from the Community Innovation Survey and a wide database on participation in FP5 and FP6. They remark that industrial participants are characterised by higher R\&D intensity and better network advantages. They are more oriented to international markets and have a greater propensity to patent. Compared with projects financed by other sources, FP projects are less market-oriented, have longer development periods, are focused on non-core technologies of participants and are related to basic research activities. From the organisation perspective, these authors find that FP projects must face a lower degree of flexibility and higher administrative burdens. According to this empirical evidence, the 
authors conclude that the participation of non-entrepreneurial organisations is increasing and, consequently, the proportion of results that could lead directly to industrial innovation has declined.

Introducing a new perspective, Dekker and Kleinknecht (2008) take into account the selfselection of applicants and analyse whether the FP participants from the Netherlands, Germany and France have better performance indicators because they participate or because they are more innovative. They confirm the existence of the self-selection bias associated with participation in the FP and estimate the impact equation correcting this aspect. Concerning the FP impact, they consider firms participating indistinctly in FP4 and FP5 and analyse the effect on innovative output, measured as logs of sales of innovative products per employee. These authors cannot corroborate a positive effect on innovative results, but they find a positive influence on $R \& D$ intensity for companies with fewer than 100 employees.

To summarise, empirical evidence on the impact of the FP seems to indicate that the main contribution of this programme to the industry participants is related to the improvement of scientific and technological capabilities and not directly to the firms' economic performance.

\section{Empirical model and data}

When analysing the impact of any public aid, the implicit question to answer is what the behaviour of a supported firm would have been if it had not received this public aid. The problem is that each firm can only be observed either in the status of receiving the public support or not; that is, we cannot directly observe the additional effect. As is well known, if aid was granted randomly to firms (or consortia), we could estimate the effect of public aid on (for instance) performance as the difference between the average one in supported and non-supported firms. However, the evidence shows that aid is not granted randomly. Therefore, to measure the effect of public aid, we need to estimate or approximate the counterfactual. That is, we have to take into account that the awarding decision by the public agency probably depends on the same firm (or consortia) characteristics that determine performance. The econometric literature has developed several methods in order 
to solve these difficulties ${ }^{2}$. One of the most used alternatives, and the one that will be followed here, is the Heckman selection model, which involves estimating what determines the receipt of the aid (the "selection equation").

Nevertheless, the application of this method is not free of difficulties. Most of the empirical studies that try to explain the impact of national or international aid programmes have information only about financed projects, and therefore are not able to distinguish between the firm's decision to apply for the aid and the agency selection among the proposals (see, for example, Blanes and Busom (2004), who refer to participation in R\&D subsidy programmes). The main disadvantage of this lack of information is that the selectivity problem is not fully considered.

However, in our database, we also have data about rejected applications. Taking this into account, we can express the probability of participation in a financed cooperative R\&D project as the following joint probability:

$$
\begin{aligned}
& \operatorname{Pr}(\text { participation }=1)=\operatorname{Pr}(\text { application }=1, \text { award }=1 \mid x)= \\
& =\operatorname{Pr}(\text { award }=1 \mid \text { application }=1, x) \cdot \operatorname{Pr}(\text { application }=1, x)
\end{aligned}
$$

Following a previous paper by Barajas and Huergo (2009), to estimate both probabilities, the empirical model includes two equations. The first describes the decision of applying for an FP cooperation project involving at least one Spanish firm. The second equation refers to the awarding by the European Commission.

Formally, we can write our model as follows. Let $i=1, \ldots, N$ index firms. The equation which describes the decision to apply for an FP cooperation project (involving at least one Spanish firm) takes the form:

$$
y_{1 i}= \begin{cases}1 & \text { if } y_{1 i}^{*}=x_{1 i} \beta_{1}+u_{1 i}>0 \\ 0 & \text { otherwise }\end{cases}
$$

where $y_{1 i}^{*}$ is a latent dependent variable, $x_{1 i}$ is the set of explanatory variables, $\beta_{1}$ is the vector of coefficients and $u_{l \mathrm{i}}$ is the error term. The firm $i$ applies within the FP if $y_{1 i}^{*}$ is positive.

\footnotetext{
2 See a detailed discussion of the different methods in the survey by Aerts, Czarnitzki and Fier (2007).
} 
Conditional on firm $i$ applying, the agency can award or reject the proposal. Again, the probability of being awarded is formalised in terms of a binary model:

$$
y_{2 i}= \begin{cases}1 & \text { if } y_{2 i}^{*}=x_{2 i} \beta_{2}+u_{2 i}>0 \\ 0 & \text { otherwise }\end{cases}
$$

where $y_{2 i}^{*}$ is the latent dependent variable, $\beta_{2}$ is the vector of coefficients, $u_{2 \mathrm{i}}$ is the error term, and $x_{2 i}$ is the set of explanatory variables which are assumed to be strictly exogenous or predetermined longer in advance. The proposal in which the Spanish firm $i$ participates is approved if $y_{2 i}^{*}$ is positive. ${ }^{3}$

Assuming than the error terms of both equations can be correlated (with correlation coefficient equal to $\rho$ ), we estimate the system of equations (1) and (2) as a probit model with sample selection by maximum likelihood (using the Heckman procedure for the binary response variable in Stata).

After the joint estimation of both equations, we proceed to estimate the impact of the supported cooperative project in terms of output. Given that the R\&D projects supported through the FP are generally long-term projects (the average duration of a project is around 24 months and before starting the project, the negotiation phase with the European Commission could also take several months), it seems reasonable to analyse its impact once the project has formally finished. To do so, the measures of output that we include in our analysis refer to the period $t+5$ relative to the awarding year.

Specifically, in the second step, we analyse how participation of the firm in an FP project affects the generation of new knowledge. This is approached by the proportion of intangible fixed assets over employment, which constitutes an indirect measure of innovation output, given that the knowledge generated in the $R \& D$ project will usually be reflected by the volume of intangibles inside the firm (especially in the case of patents and R\&D investments). Therefore, the next equation in our model is:

$$
k_{i}=p_{i}^{*} \gamma+x_{i}^{\prime} \delta+e_{i}
$$

\footnotetext{
${ }^{3}$ Notice that more than one Spanish firm can participate in the same proposal, and the same Spanish firm can participate in more than one proposal every year. To establish a clear correspondence between firms and projects, in our sample we have only included one project per firm and year.
} 
, where $k_{i}$ stands for a firm's intangible fixed assets, and $p_{i}^{*}$ denotes the predicted value for the probability of participating within the FP. We include the prediction instead of the dummy for observed participation to take care of the selectivity problem. $x_{i}$ is a vector of other control variables in equation (3).

In the last step of the model, we estimated the impact of the intangible assets, as an indicator of knowledge capital, on a firm's labour productivity, as an indicator of economic success. Therefore, if we find that intangibles are affected by participation within the FP, and that these intangibles increase productivity, the economic impact of the cooperative project will also be supported by the evidence. As a consequence, the last equation in our model takes the form

$$
g_{i}=\pi_{1} k_{i}+z_{i}^{\prime} \pi_{2}+v_{i}
$$

, where $g_{i}$ is labour productivity, $k_{i}$ is knowledge capital (represented by intangible assets) and $z_{i}$ stands for other additional controls in equation (4). We take care of the endogeneity of $k_{i}$ in this equation by using the predicted values from equation (3) in the estimation.

In equations (3) and (4), dependent variables refer to period $t+5$ relative to the awarding year. As we have explained previously, the R\&D projects supported by the FP are generally long-term, and it seems reasonable to analyse its impact once they have formally finished and firms have obtained economic returns.

To summarise, in this paper we apply a structural model which has the following basic structure: (i) firms decide whether or not to apply for a FP cooperation project; (ii) the proposal is awarded or rejected by the European Commission; (iii) the innovation activities involved in the cooperative $R \& D$ project succeed through the generation of new knowledge (represented by intangibles); (iv) the addition of this new knowledge to the production process results in productivity growth. Since we assume a recursive model structure and do not allow for feedback effects, we follow a three-step estimation procedure. In the first step, we estimate a maximum likelihood probit model with sample selection (Equations (1) and (2)). In the second step, we estimate the knowledge production function (Equation (3)) (proxied by the stock of intangible fixed assets), using the predicted value of the probability of participating within the FP to take care of the 
selectivity problem. In the last step, we estimate the productivity equation, using the proportion of intangible fixed assets as an indicator of knowledge generation.

We choose this structural model because it captures the main features of the phenomenon we want to analyse, but is parsimonious and empirically tractable with the data we have available. This recursive structure is, to a certain extent, similar to the one proposed in the well-known CDM model (Crepon et al., 1998).

\subsection{Database}

The database used here is provided by the Centre for the Development of Industrial Technology (CDTI), which is the public organisation in charge of monitoring the participation of Spanish firms within the FP. Since FP6 went into effect, the CDTI has been the organisation in charge of the maintenance and management of the information related to Spanish participation in the FP. As a consequence, the CDTI-PM database includes information about all the proposals, ${ }^{4}$ eventually granted or not, in which at least one Spanish firm participated between 1995 and 2005. This period covers part of FP4 (1994-1998), all of FP5 (1999-2002) and part of FP6 (2002-2006).

This information from the CDTI-PM database has been complemented with the SABI database that contains the company accounts of more than 1,000,000 Spanish firms between 1995 and 2007. The merger of the CDTI-PM and SABI databases has been possible because Spanish firms are identified both in the CDTI-PM and the SABI databases through their company tax codes.

From the SABI database, we have selected a control sample that takes into account the availability of data about the relevant variables for each firm. Given that Spanish firm size is smaller than the European average (European Commission, 2003), we have designed the sample selection considering a firm to be large when its number of workers exceeds 200, although the threshold in international statistics is usually set at 250 . We have chosen all companies employing more than 200 employees. Firms employing between 10 and 200 employees are selected by a random sampling scheme for each NACE class (two-digit) level,

\footnotetext{
${ }^{4}$ To guarantee the homogeneity of the sample, only Specific Targeted Research Projects (STREPs) and Integrated Projects are considered.
} 
and represent around $4 \%$ of the Spanish Central Companies Directory (CCD), which comprises all Spanish companies and their local units. This makes our control sample representative of the Spanish economy. ${ }^{5}$ Although we have information since 1995, the sample used in the empirical analysis of participation refers only to the period 1999 to 2005, given that FP5 started in 1999 and we want to take into account experience, if any, in the previous programme. In addition, as we use the forward values of output measures to capture long-term relationships, in some estimates the number of years with complete information is reduced to 4 .

Since our objective is to analyse the impact of collaboration within the FP on performance variables, our unity of analysis is the firm. In this sense, although some firms have applied in more than one proposal every year, we only consider one project per firm and year. We have given priority to those supported projects with bigger subsidies. After that, 1,555 observations have been eliminated, where 142 observations refer to supported projects. We have also excluded observations of the extreme values of employment and sales growth rates. Specifically, we have eliminated values in the extreme percentiles (1 and 99\%). In addition, we dropped negative values for productivity, tangibles and intangible fixed assets. Overall, the final sample consists of an unbalanced panel of 56,945 observations, 11,435 companies, and 2,536 proposals.

The CDTI-PM database allows us to analyse specifically those factors related to agency selection ${ }^{6}$, while the information from the joint database is used mainly to estimate the firm's decision to engage in a cooperative project, and the impact of participation on the firm's output.

\section{Results}

In this section, we present the results of the estimation of the model depicted in Section 3. As Equations (1) to (4) point out, we assume a recursive model where feedback from performance variables to the decision of applying for a FP cooperation project is not

\footnotetext{
${ }^{5}$ Coverage of the data is basically restricted to firms that have at least 10 employees (annual average), but we have also included 615 micro-companies $(0.5 \%$ of the $\mathrm{CCD}$, chosen again by means of a random sampling scheme), given that 219 applicants of cooperative FP projects belong to this category.

${ }^{6}$ Proposals are evaluated by independent experts according to some common criteria. However, such information is absent from our database.
} 
allowed. Taking this into account, we follow a three-stage estimation procedure. In the first stage, a probit model with sample selection including the decision to participate in a cooperative R\&D project within the FP and the decision of awarding by the EC are jointly estimated consistently by maximum likelihood. In the second stage, we estimate the generation of new knowledge (Equation (3)), approaching the innovation output by the intangible fixed asset and introducing the predicted value of the probability of participating within the FP as an explanatory variable. In the last stage, the productivity growth equation (4) is estimated by including a proxy of the new knowledge as an explanatory variable; specifically, we introduce the predicted value of intangible fixed assets.

\section{Cooperation within the FP}

Tables 1 and 2 show the results of the Heckman probit estimation associated with the probability of participation within the FP. The first one exhibits the coefficients of the probit model for the firm's decision to apply for an FP cooperation project (equation (1)), while the second one corresponds to the probability of being awarded the subsidy by the EC (Equation (2)). We also report marginal effects in square brackets. Notice that the correlation term $\rho$ in Table 2 is significant, pointing out the necessity of estimating a selection model for the awarding decision ${ }^{7}$.

The explanatory variables included in Equations (1) and (2) follow the selection made by Barajas and Huergo (2009) for a quite similar sample ${ }^{8}$. The results basically confirm the evidence obtained in that paper. As for the applying equation, as can be seen in Table 1, most coefficients are statistically significant, although marginal effects are small except for those variables measuring the FP experience in the previous year. In general, explanatory variables increase the probability of applying for an FP cooperation project, with the exception of the liquidity ratio, which has a negative impact, which is consistent with the idea that cooperation can be considered a strategy for avoiding financial obstacles associated with R\&D projects for firms with financial constraints.

\footnotetext{
${ }^{7}$ The Heckman procedure for the binary response variable in STATA does not take into account the panel structure of the data and the information is treated as a pool. However, in Barajas and Huergo (2009), the decision to apply has been estimated as a random-effects probit model taking into account the panel structure of the data and the results are basically the same.

${ }^{8}$ Find the exact definitions of the variables in Appendix A.
} 
Table 1: Probability of applying within the FP. Probit estimates.

\begin{tabular}{|c|c|c|c|c|}
\hline \multirow{2}{*}{\begin{tabular}{|l|} 
Time dummies \\
\end{tabular}} & \multicolumn{3}{|c|}{ Coefficient } & \multirow[t]{2}{*}{ Std. E. } \\
\hline & & & & \\
\hline Year 2000 & -0.054 & & {$[-0.003]$} & 0.038 \\
\hline Year 2001 & -0.040 & & {$[-0.002]$} & 0.037 \\
\hline Year 2002 & -0.280 & $* * *$ & {$[-0.012]$} & 0.041 \\
\hline Year 2003 & 0.055 & & {$[0.003]$} & 0.036 \\
\hline Year 2004 & -0.258 & $* * *$ & {$[-0.011]$} & 0.040 \\
\hline Year 2005 & -0.233 & $* * *$ & {$[-0.010]$} & 0.041 \\
\hline Prior experience in FP proposals & 0.564 & $* * *$ & {$[0.047]$} & 0.029 \\
\hline Granted project in previous year & 1.545 & $* * *$ & {$[0.289]$} & 0.045 \\
\hline Rejected proposal in previous year & 1.650 & $* * *$ & {$[0.315]$} & 0.030 \\
\hline Exporter & 0.125 & $* * *$ & {$[0.006]$} & 0.023 \\
\hline Liquidity ratio & -0.048 & $* *$ & {$[-0.002]$} & 0.020 \\
\hline Intangible fixed assets over employment & 0.033 & $* * *$ & {$[0.002]$} & 0.008 \\
\hline EBITDA margin & 0.232 & $* * *$ & {$[0.012]$} & 0.087 \\
\hline Stock market & 0.322 & $* * *$ & {$[0.023]$} & 0.067 \\
\hline \multicolumn{5}{|l|}{ Firm's size dummies (no. of workers) } \\
\hline From 10 to 49 & -0.239 & $* * *$ & {$[-0.011]$} & 0.041 \\
\hline From 50 to 99 & -0.351 & $* * *$ & {$[-0.014]$} & 0.044 \\
\hline From 100 to 199 & -0.395 & $* * *$ & {$[-0.016]$} & 0.045 \\
\hline More than 200 & -0.385 & $* * *$ & {$[-0.018]$} & 0.040 \\
\hline \multicolumn{5}{|l|}{ Region } \\
\hline Basque Country & 0.300 & $* * *$ & {$[0.020]$} & 0.037 \\
\hline Catalonia & 0.113 & $* * *$ & {$[0.006]$} & 0.030 \\
\hline Madrid & 0.119 & $* * *$ & {$[0.006]$} & 0.030 \\
\hline Valencia & 0.112 & $* * *$ & {$[0.006]$} & 0.042 \\
\hline \multicolumn{5}{|l|}{ High-tech services } \\
\hline Post and telecommunications & 0.603 & $* * *$ & {$[0.055]$} & 0.068 \\
\hline Computer and related activities & 0.459 & $* * *$ & [0.036] & 0.039 \\
\hline Research and development & 0.583 & $* * *$ & {$[0.053]$} & 0.072 \\
\hline \multicolumn{5}{|l|}{ High and medium-tech manufacturing } \\
\hline Chemicals and chemical products & 0.020 & & {$[0.001]$} & 0.049 \\
\hline Machinery and equipment n.e.c. & 0.020 & & {$[0.001]$} & 0.051 \\
\hline Office machinery and computers & 0.495 & $* * *$ & {$[0.041]$} & 0.144 \\
\hline Electrical machinery and apparatus n.e.c. & 0.052 & & {$[0.003]$} & 0.076 \\
\hline Radio, television and communication & 0.257 & $* * *$ & {$[0.017]$} & 0.076 \\
\hline Medical, precision and optical instruments & 0.156 & & [0.009] & 0.096 \\
\hline Motor vehicles, trailers and semi-trailers & 0.072 & & {$[0.004]$} & 0.073 \\
\hline Other transport equipment & 0.432 & $* * *$ & {$[0.034]$} & 0.079 \\
\hline Log of likelihood function & \multicolumn{4}{|c|}{$-8,190.55$} \\
\hline Number of observations & \multicolumn{4}{|c|}{56,945} \\
\hline
\end{tabular}

Marginal effects in square brackets. Std. E.: Estimated standard error. Coefficients significant at: 1\%***, 5\%**, 10\%*. All regressions include the constant. Dummies excluded for firms with fewer than 10 employees and the year 1999. Marginal effects are computed at sample means. For dummy variables, the marginal effect corresponds to the change from 0 to 1 . 
Table 2: Probability of being awarded. Probit estimates.

\begin{tabular}{|c|c|c|c|c|}
\hline \multirow{2}{*}{ Year of the application } & \multicolumn{3}{|c|}{ Coefficient } & \multirow[t]{3}{*}{ Std. E } \\
\hline & \multirow[b]{2}{*}{0.064} & \multirow[b]{3}{*}{$* *$} & \multirow[b]{2}{*}[0.007]{} & \\
\hline Year 2000 & & & & \\
\hline Year 2001 & 0.241 & & {$[0.029]$} & 0.109 \\
\hline Year 2002 & 0.149 & & {$[0.017]$} & 0.126 \\
\hline Year 2003 & -0.251 & & {$[-0.023]$} & 0.219 \\
\hline Year 2004 & 0.001 & & {$[0.000]$} & 0.217 \\
\hline Year 2005 & 0.016 & & {$[0.002]$} & 0.200 \\
\hline Participation of organisms & -0.470 & $* * *$ & {$[-0.050]$} & 0.168 \\
\hline Size (of consortium) & 0.707 & $* * *$ & {$[0.075]$} & 0.071 \\
\hline FP budget for the specific programme & -0.009 & & {$[-0.001]$} & 0.018 \\
\hline \multicolumn{5}{|l|}{ Leader nationality } \\
\hline British & -0.032 & & {$[-0.003]$} & 0.122 \\
\hline Dutch & 0.345 & $*$ & {$[0.048]$} & 0.188 \\
\hline French & 0.220 & $*$ & {$[0.028]$} & 0.127 \\
\hline German & 0.361 & $* * *$ & {$[0.051]$} & 0.113 \\
\hline Italian & -0.104 & & {$[-0.010]$} & 0.130 \\
\hline Spanish & 0.312 & $* * *$ & {$[0.042]$} & 0.087 \\
\hline \multicolumn{5}{|l|}{ Technological area } \\
\hline Aeronautic and aerospace & 0.259 & & [0.034] & 0.246 \\
\hline Agro-food & 0.261 & & {$[0.034]$} & 0.269 \\
\hline Environment and energy & 0.024 & & [0.003] & 0.230 \\
\hline ICT & 0.129 & & {$[0.015]$} & 0.217 \\
\hline Innovation programmes & 0.385 & & {$[0.055]$} & 0.335 \\
\hline New materials & 0.247 & & {$[0.032]$} & 0.195 \\
\hline Transports & 0.311 & $* *$ & {$[0.042]$} & 0.130 \\
\hline Geographical distance & -1.079 & $* * *$ & {$[-0.114]$} & 0.107 \\
\hline Prior experience in granted FP projects & 0.143 & $*$ & {$[0.017]$} & 0.080 \\
\hline Granted project in previous year & -0.031 & & {$[-0.003]$} & 0.109 \\
\hline Rho & 0.089 & $*$ & & 0.046 \\
\hline Log of likelihood function & \multicolumn{4}{|c|}{$-8,190.55$} \\
\hline Number of censored / uncensored obs. & \multicolumn{4}{|c|}{$54,409 / 2,536$} \\
\hline
\end{tabular}

Marginal effects in square brackets. Std. E.: Estimated standard error. Coefficients significant at: 1\%***, $5 \% * *, 10 \% *$. All regressions include the constant. Dummy excluded for the year 1999. Marginal effects are computed at sample means. For dummy variables, the marginal effect corresponds to the change from 0 to 1 .

When we analyse the coefficients of the time variables, we observe that firms applied in smaller proportion in 2002, 2004 and 2005. The first one corresponds to the last year of the edition of the FP4 and confirms that firms tend to submit a smaller percentage of proposals when the current programme edition is finishing, probably due to the lower number of calls for proposals. The other two dummy variables correspond to the FP6 and allow us to compare both FP5 and FP6. The results are consistent with the fact that, in comparison with FP5, FP6 was less favourable to the technological objectives of Spanish firms, which consequently applied in smaller proportions. 
As expected, previous experience in FP proposals increases the probability of applying in future editions and especially when the prior experience took place during the previous year. Since the application process within the FP is very costly, companies in consortia that have been rejected will try to profit from the accumulated knowledge, applying to the following calls. The probability of engaging in an FP project increases about 30 points for firms with experience in the last year, while it increases almost five points for firms with experience in previous editions of the FP.

With respect to the rest of the explanatory variables, exporters, firms that are on the stock market, and companies that present a higher ratio between intangible fixed assets and employment, are also more likely to apply. The earnings in terms of sales (approached by EBITDA), as a measure of ex-ante firm market power, also present a positive effect. This result is coherent with the Schumpeterian hypothesis that the less competitive the markets are, the more incentives for firms to innovate (and to participate in R\&D consortia) since they are better able to capture innovation benefits. However, this empirical evidence could also be supporting the existence of an informal competitive process among proponents in order to take part in those FP consortia led by the most reputed organisation. Thus, the most profitable firms have a higher probability of being selected by consortia coordinators.

The coefficients of the set of size dummies indicate a negative impact of size on the probability of applying. This unexpected result can be affected by the fact that our control sample is biased towards large firms, which are chosen on the basis of a census, while firms employing between 10 and 200 employees are selected by a random sampling scheme. Additional work would be necessary to study this result more closely ${ }^{9}$.

With respect to the geographical indicators, firms located in the Basque Country, Catalonia, Madrid and Valencia show higher probabilities of submitting an application, which is consistent with the major concentration of technological firms in these regions. The last rows of Table 1 present the coefficients of industry dummies ${ }^{10}$. Firms that carry

\footnotetext{
${ }^{9}$ Barajas and Huergo (2009) present complementary estimations for two sub-samples: small and medium size enterprises (SME), and large firms. They found a non-linear effect of size which is negative for the SME and positive for large firms.

${ }^{10}$ We also include some other industry dummies with statistically significant effects. Specifically, Education, Clothing apparel and footwear and Other business activities, which include architectural and engineering activities and related technical consultancy, should be noted. An opposite case is the Hotels and restaurants industry, with a lower probability of participating in technological projects. In reference to the Energy sector, both FP4 and FP5 had specific programmes for the development of sustainable energies, which increased the occasions for firms to present proposals. The results are available from the authors upon request.
} 
out high-tech activities are also more prone to become proponents. The probability of engaging in an FP project increases more than 5 points for companies in the Post and telecommunications service sector and $\mathrm{R} \& \mathrm{D}$ sector. Also, affiliation to Computer and related activities, Office machinery and computers, and the transport equipment industry increases the probability of applying by about 4 points.

Table 2 shows the coefficients corresponding to the estimation of the equation for the probability of being awarded aid by the EC. Again, the results confirm the evidence provided by Barajas and Huergo (2009). Firstly, the presence of public organisations within a consortium and the distance among the partners negatively affect the viability of the proposal. Both variables can be reflecting the existence of coordination costs. With respect to the participation of non-entrepreneurial organisations, these costs could be associated with the differences in private and public cooperation routines, especially concerning the protection of innovation results.

Secondly, the inclusion of a new member in the consortium increases the probability of being supported by 7.5 points. In this case, the required technological diversity of the research equipment seems to exceed the coordination cost associated with each additional partner.

Thirdly, the probability of being supported increases when the project belongs to the Transport area ${ }^{11}$, and especially when the proposal is led by a German organisation., Spanish firms that participate in consortia led by companies or organisations from Germany - a very active country within the FP- probably earn greater experience, enjoy better coordination routines, and therefore are more likely to receive aid from the EC.

Previous experience in FP projects has less impact on the probability of being supported than on the probability of applying. It seems clear that "learning-by-doing" is a more relevant factor in explaining the decision to participate due to the complexity of the FP procedures and the need to exploit scope economies once the effort to apply is made and the consortium is shaped.

\footnotetext{
${ }^{11}$ Most of the total budget of the FPs is allocated to information and communication technologies. Therefore, it seems that the EU gives priority to these technological areas. Our result that only firms which carry out FP programmes in Transport show a greater probability of receiving aid can be a consequence of the criteria followed to eliminate the firms which have more than one project. Most of the dropped observations are projects belonging to ICT, Transport and Aeronautical technologies areas.
} 
Finally, although the temporal dummies which indicate the year in which the firm applied are jointly significant, they do not present significant coefficients in any year. That is, according to these results, there are no specific differences in the probability of being supported in both FP5 and FP6.

\section{Impact on knowledge accumulation}

We next proceed to estimate Equation (3). As already stated, to capture the impact of supported cooperative projects, our measure of technological output is the proportion of intangible fixed assets over employment. We assume that this constitutes an indirect measure of innovation output, given that the knowledge generated in the R\&D project will usually be reflected by the volume of intangibles inside the firm, especially if the new knowledge is protected through patents ${ }^{12}$. In Table 3, we describe the variables used in the following econometric analysis.

The firms' technological capabilities are represented by their intangible fixed assets, given the intangible character of $R \& D^{13}$. The difference of means test confirms that the average of this variable in the sample is higher for participants within the FP than for nonparticipants. The proportion of intangibles over employment is slightly lower for participants. On the contrary, the percentage of tangible fixed assets per employee is higher for supported firms. Participants seem to be more productive, although the difference is small.

In addition, we consider a set of geographical dummies to be explanatory variables, as the more technological Spanish firms tend to locate in specific regions. As we can see, for participants, the percentage of companies located in Madrid, Catalonia and the Basque Country (regions with R\&D intensities above the national average), is higher than for nonparticipants.

We also take into account whether the firm's activity corresponds to a high-tech service sector or a high or medium-tech manufacturing sector according to the OCDE

\footnotetext{
${ }^{12}$ Most previous empirical evidence approaches the new knowledge by other technological outputs as product and process innovations, or sales generated by new products. However, this information is not available in our database.

${ }^{13}$ Spanish accounting rules allow for the capitalisation of R\&D expenditures under certain conditions (mainly when there are reasonable expectations of marketable results).
} 
classification. The frequencies in Table 3 reflect a high presence of these activities among participants, especially in high-tech services.

Table 3: Features of the participants. Descriptive statistics

\begin{tabular}{|l|c|c|c|}
\hline Means of quantitative variables: & Total sample & Participants & Non-participants \\
\hline Intangible Fixed Assets $(€)$ & $3,120.05$ & $7,362.01$ & $3,091.83$ \\
Intangible Fixed Assets over Employment $(€)$ & 13.93 & 11.91 & 13.94 \\
Tangible Fixed Assets $(€)$ & $22,272.04$ & $108,593.5$ & $21,697.33$ \\
Tangible Fixed Assets over Employment $(€)$ & 76.49 & 127.38 & 76.15 \\
Productivity (sales over employment) $(€)$ & 247.17 & 268.77 & 247.02 \\
Firm size (no of employees) & 355.41 & 877.41 & 351.93 \\
\hline Frequencies of binary variables: & Total sample & Participants & Non-participants \\
\hline Stock market & 1.25 & 6.87 & 1.21 \\
Exporter & 49.81 & 66.76 & 49.70 \\
Basque Country & 7.51 & 15.93 & 7.45 \\
Catalonia & 24.62 & 27.20 & 24.61 \\
Madrid & 23.56 & 32.42 & 23.50 \\
Valencia & 9.67 & 6.87 & 9.69 \\
High and medium-tech manufacturing & 17.07 & 25.55 & 17.01 \\
High-tech services & 5.88 & 15.66 & 5.82 \\
\hline
\end{tabular}

A firm's export activity is captured through a binary variable that takes the value one if the firm is an exporter during the period. As we can see in Table 3, the percentage of exporters among participants is 16 points higher than among non-applicants.

As an additional control variable, we include a dichotomy variable that reflects whether the firm is listed on the stock market. This kind of company is usually financially more consolidated and international funds could be less attractive to it. However, firms on the stock market tend to show more formalised quality procedures and therefore could have more systematic collaboration routines. In our sample, stock market companies are more frequent among participants.

The empirical results are reported in Table 4. We assume that all explanatory variables are strictly exogenous and the estimation is carried out by OLS using a random effect model for panel data. We have included some control variables in the specification like time, size, export activity, industries (to capture some sector-specific effects as technological opportunities) and regional (to control for the concentration effect in some Spanish areas) dummies. 
The coefficients reported in this table are semi-elasticities because the dependent variable is measured in logarithms. Specifically, as all explanatory variables are dummies, they show the variation rate in unitary terms of intangible fixed assets per employee when the explanatory variable changes from 0 to 1 .

Due to the pre-competitive orientation of FP projects, we assume that their results will have effects in the long term. In this sense, our dependent variable refers to the period $t+5$, where $t$ is the awarding year ${ }^{14}$.

Table 4: Intangible fixed assets per employee $(t+5)$

\begin{tabular}{|c|c|c|c|c|c|c|}
\hline & \multicolumn{3}{|c|}{ (1) } & \multicolumn{3}{|c|}{ (2) } \\
\hline & \multicolumn{2}{|c|}{ Coefficient } & Std. E. & \multicolumn{2}{|c|}{ Coefficient } & Std. E. \\
\hline FP participant (observed) & 0.083 & & 0.061 & & & \\
\hline FP participant (predicted) & & & & 0.394 & $* *$ & 0.172 \\
\hline Stock market & 1.174 & $* * *$ & 0.182 & 1.169 & $* * *$ & 0.181 \\
\hline Exporter & 0.156 & $* * *$ & 0.030 & 0.154 & $* * *$ & 0.030 \\
\hline \multicolumn{7}{|l|}{ Firm size dummies ( $\mathrm{n}^{\circ}$. of workers) } \\
\hline From 10 to 49 & -0.104 & $* *$ & 0.048 & -0.104 & $* *$ & 0.048 \\
\hline From 50 to 99 & -0.201 & *** & 0.052 & -0.201 & $* * *$ & 0.052 \\
\hline From 100 to 199 & -0.279 & *** & 0.053 & -0.280 & $* * *$ & 0.053 \\
\hline More than 200 & -0.358 & $* * *$ & 0.053 & -0.358 & $* * *$ & 0.053 \\
\hline \multicolumn{7}{|l|}{ Region } \\
\hline Basque Country & 0.057 & & 0.058 & 0.052 & & 0.058 \\
\hline Catalonia & 0.246 & $* * *$ & 0.039 & 0.245 & $* * *$ & 0.039 \\
\hline Madrid & 0.117 & *** & 0.039 & 0.116 & $* * *$ & 0.039 \\
\hline Valencia & 0.030 & & 0.049 & 0.029 & & 0.049 \\
\hline High and medium-tech manufacturing & 0.073 & $* * *$ & 0.041 & 0.072 & $*$ & 0.041 \\
\hline High-tech services & 0.318 & $* * *$ & 0.070 & 0.314 & $* * *$ & 0.070 \\
\hline Sigma of $\mathrm{u}$ & \multicolumn{3}{|c|}{1.210} & \multicolumn{3}{|c|}{1.209} \\
\hline Rho & \multicolumn{3}{|c|}{0.868} & \multicolumn{3}{|c|}{0.867} \\
\hline Number of observations & \multicolumn{3}{|c|}{23,089} & \multicolumn{3}{|c|}{23,089} \\
\hline
\end{tabular}

Std. E.: Estimated standard error. Coefficients significant at: 1\%***, 5\%**, 10\%*. All regressions include the constant and temporal dummies. Dummy excluded for firms with fewer than 10 workers.

We are interested in comparing the effect of predicted participation versus observed participation. In Table 4, the first column corresponds to the model in which we included the dummy for observed participation (yes /no) as an explanatory variable, while in column (2), this variable is substituted by the prediction obtained in the previous step (estimations of Equations (1) and (2)). It should be remarked that taking the selection problem into

\footnotetext{
${ }^{14}$ Most empirical evidence also recognises the need to measure effects using a long-term perspective (see Benfratello and Sembenelli, 2002; Dekker et al., 2008).
} 
account is relevant: whereas the coefficient for observed participation is not significant, the predicted probability of participation positively affects our technological output. Specifically, being a firm that cooperates in an FP increases the ratio of intangible fixed active over employment almost $40 \%$. This result is in concordance with those presented by Dekker et al (2008).

With respect to the control variables, industry dummies are highly significant. Firms belonging to high-tech manufacturing and services and medium-tech manufacturing have a higher potential of generating technological outputs. The level of intangible fixed assets per employee increases $7 \%$ in manufacturing and more than $31 \%$ in services. As expected, we find regional differences in terms of technological output. Firms located in Madrid and Catalonia present a bigger level of intangible assets.

We obtain a negative effect of the size dummies. Most previous empirical evidence for Spanish manufacturing provides a positive relationship between firm size and the probability of being engaged in technological activities and obtaining product or process innovations, stressing the capacity of large firms to exploit economies of scale. However, a negative relationship is found in terms of innovation intensity: large firms present a lower proportion of resources in $R \& D$ with respect to smaller firms.

Finally, being a company listed on the stock market or being an exporter also positively affects the generation of new knowledge. Specifically, firms operating in international markets register an increment of $15 \%$ in the ratio of intangible fixed assets over employment.

\section{Impact on labour productivity}

The variable used to analyse the impact of cooperation on economic performance is labour productivity, measured as the ratio between total sales and number of employees. Estimations of the productivity equation (4) are shown in Table 5. Again, the estimation is carried out by OLS using a random effect model for panel data.

The coefficients reported in Table 5 are elasticities or semi-elasticities, since the dependent variable is the logarithms of sales per employee. In addition to control variables referring to size, industry, year, and firm location, we have included a proxy of physical capital 
intensity in the model, measured throughout the variable "tangible fixed asset per employee". Finally, to capture the effect of knowledge accumulation on productivity, we have included the predicted value of "intangible fixed assets over employment" from Equation (3).

By means of these estimations, we analyse whether participation within the FP has not only an indirect effect but also a direct effect on firms' economic success. As we have demonstrated in the previous section, the predicted probability of being awarded aid enhances the ratio of intangible fixed assets. If we find a positive relationship between this proxy of technological output and the level of productivity, the indirect economic impact of cooperation on productivity would be confirmed. If we find that FP participation also has a significant effect on productivity, an additional direct effect of cooperation on economic performance would be corroborated.

In the first column of Table 5, we present the obtained results, considering neither the observed nor the predicted participation to be explanatory variables. Under these conditions, the impact of the predicted value of "intangible fixed assets per employee" on productivity is clearly significant, reflecting a difference in favor of innovative firms. Specifically, if the ratio of intangible assets duplicates, it causes productivity to grow more than $12 \%$ (see Table 5). As firms participating in FP present higher technological outputs, this result supports an indirect effect of cooperation on this performance variable.

In columns (2) and (3), the specification also includes the dummy for observed and predicted participation, respectively. As can be seen, both of them are not significant. Therefore, it seems that cooperation in FP does not have a direct effect on performance variables. This result is in concordance with those presented by Benfratello and Sembenelli (2002). Using a different methodology, they do not find significant differences in the labour productivity of firms that have participated in FP 3 and FP 4. In a similar way, Dekker et al (2008) confirm that innovative output - sales of innovative product per employee- is not enhanced by participation in the EU FP in France, Germany and The Netherlands.

Additionally, there are no changes in the coefficients of the rest of variables. Capitalintensive firms - approached by the ratio "tangible fixed assets per employee" - are also 
more productive. As in previous empirical evidence, exporting firms are also more efficient than non-exporting firms.

Table 5: Labour productivity $(t+5)$

\begin{tabular}{|c|c|c|c|c|c|c|c|c|}
\hline & \multicolumn{2}{|l|}{ (1) } & \multicolumn{3}{|c|}{ (2) } & \multicolumn{3}{|c|}{ (3) } \\
\hline & Coefficient & Std. E. & Coeffici & ient & Std. E. & Coeffic & ient & Std. E. \\
\hline FP participant (observed) & & & 0.010 & & 0.032 & & & \\
\hline FP participant (predicted) & & & & & & 0.044 & & 0.070 \\
\hline $\begin{array}{l}\text { Intangible Fixed Assets per employee } \\
\text { (predicted) }(\mathrm{t}+5)\end{array}$ & $0.121 * * *$ & 0.009 & 0.120 & $* * *$ & 0.012 & 0.120 & $* * *$ & 0.012 \\
\hline Tangible Fixed Assets per employee $(t+5)$ & $0.336 * * *$ & 0.005 & 0.336 & $* * *$ & 0.014 & 0.336 & $* * *$ & 0.014 \\
\hline Stock market & -0.110 & 0.089 & -0.111 & & 0.168 & -0.111 & & 0.168 \\
\hline Exporter & $0.381 * * *$ & 0.022 & 0.381 & $* * *$ & 0.025 & 0.381 & $* * *$ & 0.025 \\
\hline \multicolumn{9}{|l|}{ Firm size dummies ( $\mathrm{n}^{\circ}$ of workers) } \\
\hline From 10 to 49 & $0.079 * * *$ & 0.024 & 0.079 & $* *$ & 0.036 & 0.079 & & 0.036 \\
\hline From 50 to 99 & $0.097 * * *$ & 0.027 & 0.097 & $* *$ & 0.038 & 0.097 & $* *$ & 0.038 \\
\hline From 100 to 199 & $0.122 * * *$ & 0.028 & 0.122 & $* * *$ & 0.039 & 0.122 & $* * *$ & 0.039 \\
\hline More than 200 & $0.130 * * *$ & 0.028 & 0.130 & $* * *$ & 0.039 & 0.130 & $* * *$ & 0.039 \\
\hline \multicolumn{9}{|l|}{ Region } \\
\hline Basque Country & $0.176 * * *$ & 0.042 & 0.176 & $* * *$ & 0.039 & 0.175 & $* * *$ & 0.039 \\
\hline Catalonia & $0.195 * * *$ & 0.028 & 0.195 & $* * *$ & 0.030 & 0.195 & $* * *$ & 0.030 \\
\hline Madrid & $0.344 * * *$ & 0.028 & 0.344 & $* * *$ & 0.031 & 0.344 & $* * *$ & 0.031 \\
\hline Valencia & 0.016 & 0.037 & 0.016 & & 0.040 & 0.016 & & 0.040 \\
\hline High and medium-tech manufacturing & $0.152 * * *$ & 0.029 & 0.152 & $* * *$ & 0.028 & 0.152 & $* * *$ & 0.028 \\
\hline High-tech services & $-0.094 * *$ & 0.047 & -0.094 & $* *$ & 0.046 & -0.094 & $* *$ & 0.046 \\
\hline Sigma of $\mathrm{u}$ & \multicolumn{2}{|c|}{0.889} & \multicolumn{3}{|c|}{0.889} & \multicolumn{3}{|c|}{0.889} \\
\hline Rho & \multicolumn{2}{|c|}{0.894} & \multicolumn{3}{|c|}{0.894} & \multicolumn{3}{|c|}{0.894} \\
\hline Number of observations & \multicolumn{2}{|c|}{22,985} & \multicolumn{3}{|c|}{22,985} & \multicolumn{3}{|c|}{22,985} \\
\hline
\end{tabular}

Std. E.: Estimated standard error. Coefficients significant at: 1\%***, 5\%**, 10\%*. All regressions include the constant and temporal dummies. Dummy excluded for firms with less than 10 workers.

With respect to the size dummies, we find a positive linear relationship between firm size and productivity. We also obtain geographical differences in terms of productivity. Firms located in Catalonia, the Basque Country and Madrid show a higher productivity than the rest of the firms. As expected, firms from high-tech and medium-tech manufacturing industries present larger levels of productivity. However, the opposite happens with firms in high-tech services.

Finally, as a robustness check we estimate the model using the growth rate of labour productivity as a dependent variable in Equation (4) ${ }^{15}$. In this case, intangible fixed assets per employee are also included in growth rates in Equation (3). The results confirm the

\footnotetext{
${ }^{15}$ See the results of the estimates for Equations (3) and (4) in Tables B.1 and B.2 of Appendix B.
} 
positive impact of cooperation within the FP on the technological capacity of firms and the indirect effect of participating in the FP on labour productivity through intangible fixed assets.

\section{Conclusions}

The objective of this paper is to analyse the effects of $R \& D$ cooperation on economic performance. Empirical analysis is focused on consortia supported by the R\&D Framework Programme (FP) of the European Union and, more specifically, on Spanish firms participating during the period 1995-2005.

In general, literature confirms the existence of a positive relationship between R\&D cooperation and innovative results, but the effect on economic performance is not so evident. Taking into account different types of cooperation processes, empirical evidence seems to corroborate that the more market-oriented the cooperation, the higher the probability of finding positive economic effects (Benfratello and Sembenelli, 2002; Cincera et al., 2003; Belderbos et al., 2004).

Previous empirical analyses agree about the positive effect of the cooperation carried out within the FP on variables related to technological capabilities (Georghiou et al., 1992; Luukkonen, 1998; Arnold et al., 2008; Polt et al., 2008; Dekker and Kleinknecht, 2008), but evidence about the effect on economic performance is scarce. Considering the specific features of the FP (ambitious projects; consortia shaped by different types of organisations located in different countries; long-term periods; pre-competitive orientation in most of the cases), it is obvious that the economic effect of this kind of project should be analysed from a different perspective.

In this respect, one of the main contributions of the present paper is the application of a recursive model structure to capture the relationship between cooperation, knowledge generation and economic results. The model has the following basic structure: (i) firms decide whether or not to apply for a FP cooperation project; (ii) the proposal is awarded or rejected by the European Commission; (iii) the innovation activities involved in the cooperative $\mathrm{R} \& \mathrm{D}$ project succeed through the generation of new knowledge (represented 
by intangibles); (iv) the addition of this new knowledge to the production process causes productivity growth.

With respect to participation within the FP, the results confirm the evidence obtained in a previous paper by Barajas and Huergo (2009) about the determinants of applying in the FP and being awarded aid by the European Commission. Moreover, we have corroborated that the self-selection bias exists and, thus, we have estimated the impact equation by alternatively using the predicted and the observed probability. Going one step further, we have confirmed that the predicted probability of participating in the FP has a positive impact on firms' technological capabilities. Specifically, five years after the project is awarded aid, the ratio of intangible fixed assets over employment increases almost $40 \%$.

The variable used to analyse the impact of cooperation on economic performance is labour productivity, measured as the ratio between sales and employment. The impact of the predicted value of "intangible fixed assets over employment" on productivity is clearly significant. Specifically, if the ratio of "intangible fixed assets over employment" duplicates, it causes productivity to grow more than $12 \%$ five years after awarding aid to the project. This result supports an indirect effect of participating in the FP on firms' performance, captured throughout labour productivity.

From the aforementioned evidence, we can draw some conclusions regarding the interest of policy makers. The key idea supported by the study is the existence of a positive relationship between participation in FP consortia and firms' economic performance. Nevertheless, this effect is not as direct as in other public programmes, such as Eureka (Benfratello and Sembenelli, 2002). In this respect, it is necessary to take into account that the evaluation criteria followed in the FP refers to scientific and technological excellence, coordination abilities of the consortium, European added value (in terms of critical mass of resources mobilised and contribution to Community policies) and potential for disseminating the knowledge and achieving innovations ${ }^{16}$. Therefore, results must be assessed according to these criteria.

\footnotetext{
${ }^{16}$ Rules for Participation in the Sixth FP (Regulation (EC) No 2321/2002, Article 10). These criteria are quite similar to the ones of FP5.
} 
Obviously, the ideal situation is to attain all those objectives, but the fact is that the market is not always the immediate recipient of research results, especially if we are talking about border research. Thus, the direct impact of the FP seems to be related to the improvement in innovative capabilities that, to a large extent, are intangible assets, which are difficult to measure. Considering intangible assets introduced in accounting, our work has demonstrated that participation in the FP has a positive impact. The issue from the point of view of policy makers is how to capture the impact in the rest of the intangible assets, following objective and efficient criteria. Nowadays, surveys and interviews seem to be the best option in order to complement the analysis of financial information, since accounting systems are only valid instruments for evaluating some intangible assets, such as capitalised $R \& D$ expenditure, patents and software.

The second conclusion is that the economic impact of the FP should be evaluated from a long-term perspective once the specific project is finished and the market dynamic has allowed firms to introduce innovations. Otherwise, impact assessments could being ignoring a relevant contribution on firms' performance. 


\section{References}

Abramovsky, L., E. Kremp, A. López, T. Schmidt and H. Simpson (2009), "Understanding co-operative R\&D activity: evidence from four European countries", Economics of Innovation and New Technology, forthcoming.

Aerts, K., Czarnitzki, D., and A. Fier (2007), "Evaluación econométrica de las políticas públicas de I+D: situación actual". In: Heijs, J. and Buesa, M. (Eds.), Cooperación en innovación en España y el papel de las ayudas públicas. (79-104). Instituto de Estudios Fiscales, Madrid.

Arnold, E., Åström, T., Boekholt, P., Brown, N., Good, B., Holmberg, R., Meijer, I. and G. van der Veen, (2008), Impacts of the Framework Programme in Sweden. VINNOVA, Stockholm.

Aschhoff, B. and T. Schmidt (2008), "Empirical Evidence on the Success of R\&D Cooperation- Happy Together?", Review of Industrial Organization 33 (1), 41-62.

Barajas, A., and E. Huergo (2009): "International R\&D Cooperation within the EU Framework Programme: Empirical Evidence for Spanish Firms", Economics of Innovation and New Technology, forthcoming.

Belderbos, R., Carree, M., Diederen, B., Lokshin, B. and R. Veugelers (2004), "Heterogeneity in R\&D cooperation strategies", International Journal of Industrial Organization 22, 1237- 1263.

Benfratello, L. and A. Sembenelli (2002), "Research joint ventures and firm level performance", Research Policy 31, 493-507.

Blanes, J.V., and I. Busom (2004), "Who participates in R\&D subsidy programs? The case of Spanish manufacturing firms", Research Policy 33, 1459-76.

Breschi, S. and L. Cusmano (2006), "Unveiling the texture of a European Research Area. Emergence of oligarchic networks under the EU Framework Programmes" in Caloghirou, Y; A. Constantelou and N.S. Vonortas (eds.), Knowledge Flows in European Industry, Routledge, Oxon.

Cassiman, B., and R. Veugelers (2002), "R\&D Cooperation and Spillovers: Some Empirical Evidence from Belgium", American Economic Review 92(4), 1169-1184.

Cincera, M., Kempen, L., Van Pottelsberghe, B., Veugelers, R. and C. Villegas (2003), "Productivity Growth, R\&D and the role of international collaborative agreements: some evidence for Belgian Manufacturing companies", Brussels Economic Review 46(3), 107-140

Crepon, B., Duguet, E., and J. Mairesse (1998), "Research, innovation and productivity: an econometric analysis at the firm level", Economics of Innovation and New Technology 7, 115-158.

Dekker, R. and A.H. Kleinknecht (2008), "The EU Framework Programs: Are they worth doing?”. MPRA Paper, 8503. University of Munich.

DTI-Office of Science and Technology (2004), Targeted Review of Added Value Provided by International R\&D Programmes, London. http://www.berr.gov.uk/files/file14840.pdf

European Commission (2009). Evaluation of the Sixth Framework Programmes for Research and Technological Development. 2002-2006. Report of the Expert Group. http://ec.europa.eu/research/reports/2009/pdf/fp6_evaluation_final_report_en.pdf

European Commission (2003): SMEs in Europe 2003.

Faems, D., Van Looy, B. and K. Debackere (2005), "The role of interorganizational collaboration within innovation strategies: towards a portfolio approach", Journal of Product Innovation Management 22(3), 238-250. 
Georghiou, L. et al. (1992), The impact of EC policies for RTD upon S\&T in the UK, A report prepared for DGXII of the Commission of the European Communities and the UK Office of Science and Technology, by PREST, University of Manchester and SPRU, University of Sussex.

Griliches, Z. (1992), "The search for R\&D spillovers", Scandinavian Journal of Economics 94, Supplement, 29-47.

Griliches, Z. and J. Mairesse (1984), "Productivity and R\&D at the Firm level", in Z. Griliches (ed.), R\&D, Patents and Productivity, 339-74. Chicago University Press, Chicago.

Grossman, G. and Helpman, E. (1991), "Expanding Product Variety" en Innovation and Growth in the Global Economy, MIT Press, Cambridge.

Jaffe, A. (1986), "Technological opportunity and spillovers of R\&D: Evidence from firms' patents, profits and market value", American Economic Review 76, 984-1001.

Lööf, H. and A. Broström (2008), "Does knowledge diffusion between university and Industry increase innovativeness?", The Journal of Technology Transfer 33(1), 73-90

Lööf, H. and A. Heshmati (2002), "Knowledge capital and performance heterogeneity: a firm-level innovation study". International Journal of Production Economics 76(1), $61-85$.

López, A. (2008), "Determinants for R\&D cooperation: Evidence from Spanish manufacturing firms", International Journal of Industrial Organisation 26(1), 113136.

Luukkonen T. (1998), "The difficulties in assessing the impact of EU framework programmes", Research Policy 27, 599-610.

Luukkonen T. (2000), “Additionality of EU Framework Programmes”, Research Policy 29, 711-724.

Mohnen, P. (1996), "R\&D Externalities and Productivity Growth", STI Review, OECD 18, 39-66.

Nadiri M.I. (1993), "Innovations and technological spillovers", NBER Working Paper 4423, Cambridge, MA.

Polt, W., Vonortas, N. and R. Fisher (2008), Innovation Impact, Final report to the European Commission, Brussels: DG Research.

Roediger-Schluga, T. and M.J. Barber (2006), "The structure of R\&D collaboration networks in the European Framework Programmes", UNU-Merit Working Paper Series 2006-36.

Romer, P. (1990), "Endogenous Technical Change", Journal of Political Economy, 5 (2), S71-S102.

Siebert, R. (1996), "The Impact of Research Joint Ventures on Firm Performance: An Empirical Assessment", WZB Working Paper FS IV 96 - 13

Solow, R. (1957), "Technical Change and the Aggregated Production Function", Review of Economics and Statistics 39, 312-20.

Verspragen, B. (1995), "R\&D and Productivity: A Broad Cross-Section Cross-Country Look", Journal of Productivity Analysis 6, 117-35. 


\section{Appendix A: Definition of variables}

\begin{tabular}{|c|c|}
\hline EBITDA margin & Earnings Before Interest, Taxes, Depreciation and Amortization divided by sales. \\
\hline Exporter & Company exports during the period. \\
\hline Firm size & Firm's number of employees in the current year $(<10,10-49,50-99,100-199,200+)$ \\
\hline FP budget for the specific programme & Percentage of the total FP budget allocated to each specific programme. \\
\hline Geographical distance & $\begin{array}{l}\text { Percentage of partners from Northern Europe, Eastern Europe and non-European } \\
\text { countries in the total number of partners. The percentage is multiplied by } 2 \text { or } 3 \text { if the } \\
\text { partners are, respectively, from } 2 \text { or } 3 \text { of the aforementioned geographical areas. }\end{array}$ \\
\hline Granted project in the previous year & $\begin{array}{l}\text { At least one of the Spanish firms involved in the consortium participated in a granted } \\
\text { project the previous year. }\end{array}$ \\
\hline High-tech services & Company belongs to the high-tech services (NACE2 codes $64,72,73$ ). \\
\hline High and medium-tech manufacturing & $\begin{array}{l}\text { Company belongs to any high or medium-tech manufacturing sectors (NACE2 codes } \\
24,29,30,31,32,33,34,35) \text {. }\end{array}$ \\
\hline Intangible fixed assets per employee & $\begin{array}{l}\text { Ratio between intangible fixed assets and total employment in the current year (in } \\
\text { logs.) }\end{array}$ \\
\hline Labour productivity & Sales per employee (in logs.) \\
\hline Leader nationality & The leader of the consortium is (British, Dutch, French, German, Italian, Spanish). \\
\hline Liquidity ratio & Shareholders' funds in non-current liabilities in the current year \\
\hline Participation of organisations & $\begin{array}{l}\text { Ratio between the number of non-entrepreneurial organisations and the total number of } \\
\text { consortium members in the proposal. }\end{array}$ \\
\hline Prior experience in FP proposals & The Spanish firm applied to the FP in the edition previous to the current one. \\
\hline Prior experience in FP granted projects & $\begin{array}{l}\text { At least one of the Spanish firms involved in the consortium participated in a } \\
\text { cooperative project financed during the FP edition previous to the current one. }\end{array}$ \\
\hline Region & Firm is located in (the Basque Country, Catalonia, Madrid, Valencia). \\
\hline Rejected proposal in the previous year & $\begin{array}{l}\text { At least one of the Spanish firms involved in the consortium participated in a rejected } \\
\text { project during the previous year. }\end{array}$ \\
\hline Size of the consortium & $\begin{array}{l}\text { Total number of members (firms, public organisations or other institutions) in the } \\
\text { consortium (in logs). }\end{array}$ \\
\hline Stock market & Company is listed on the stock market. \\
\hline Tangible fixed assets per employee & Ratio between tangible fixed assets and total employment in the current year (in logs.) \\
\hline Technological area & $\begin{array}{l}\text { Project is related to (ICT, new materials, environment and energy, transport, agro-food, } \\
\text { aeronautic and aerospace, innovation programmes). }\end{array}$ \\
\hline
\end{tabular}


Appendix B: Complementary estimates

Table B.1: Growth of intangible fixed assets per employee $(t+5)$

\begin{tabular}{|c|c|c|c|c|c|c|}
\hline & \multicolumn{3}{|c|}{ (1) } & \multicolumn{3}{|c|}{ (2) } \\
\hline & Coefficie & & Std. E. & Coeffici & ient & Std. E. \\
\hline FP participant (observed) & 0.094 & & 0.065 & & & \\
\hline FP participant (predicted) & & & & 0.355 & $* *$ & 0.158 \\
\hline Stock market & 0.037 & & 0.042 & 0.034 & & 0.042 \\
\hline Exporter & -0.011 & & 0.008 & -0.012 & & 0.008 \\
\hline \multicolumn{7}{|l|}{ Firm size dummies ( $\mathrm{n}^{\circ}$. of workers) } \\
\hline From 10 to 49 & 0.040 & & 0.028 & 0.041 & & 0.028 \\
\hline From 50 to 99 & 0.034 & & 0.028 & 0.035 & & 0.028 \\
\hline From 100 to 199 & 0.022 & & 0.027 & 0.022 & & 0.027 \\
\hline More than 200 & 0.023 & & 0.027 & 0.023 & & 0.027 \\
\hline \multicolumn{7}{|l|}{ Region } \\
\hline Basque Country & -0.038 & ** & 0.016 & -0.041 & ** & 0.016 \\
\hline Catalonia & -0.034 & *** & 0.010 & -0.034 & **** & 0.010 \\
\hline Madrid & -0.038 & **** & 0.010 & -0.039 & **** & 0.010 \\
\hline Valencia & 0.007 & & 0.013 & 0.007 & & 0.013 \\
\hline High and medium-tech manufacturing & -0.003 & & 0.010 & -0.004 & & 0.010 \\
\hline High-tech services & -0.033 & $*$ & 0.017 & -0.036 & $* *$ & 0.018 \\
\hline Sigma of $u$ & \multicolumn{3}{|c|}{0.027} & \multicolumn{3}{|c|}{0.029} \\
\hline Rho & \multicolumn{3}{|c|}{0.002} & \multicolumn{3}{|c|}{0.003} \\
\hline Number of observations & \multicolumn{3}{|c|}{22,277} & \multicolumn{3}{|c|}{22,277} \\
\hline
\end{tabular}

Std. E.: Estimated standard error. Coefficients significant at: 1\%***, 5\%**, 10\%*. All regressions include the constant and temporal dummies. Dummy excluded for firms with fewer than 10 workers. 
Table B.2: Labour productivity growth $(t+5)$

\begin{tabular}{|c|c|c|c|c|c|c|c|c|c|}
\hline & \multicolumn{3}{|c|}{ (1) } & \multicolumn{3}{|c|}{ (2) } & \multicolumn{3}{|c|}{ (3) } \\
\hline & \multicolumn{3}{|c|}{ Coefficient Std. E. } & \multicolumn{3}{|c|}{ Coefficient Std. E. } & \multicolumn{2}{|c|}{ Coefficient } & \multirow[t]{2}{*}{ Std. E. } \\
\hline FP participant (observed) & & & & -0.006 & & 0.037 & & & \\
\hline FP participant (predicted) & & & & & & & -0.015 & & 0.080 \\
\hline $\begin{array}{l}\text { Growth of intangible fixed assets per } \\
\text { employee, predicted }(t+5)\end{array}$ & 0.375 & *** & 0.113 & 0.381 & $* * *$ & 0.116 & 0.389 & $* * *$ & 0.144 \\
\hline $\begin{array}{l}\text { Growth of tangible fixed assets per } \\
\text { employee }(t+5)\end{array}$ & 0.446 & **** & 0.026 & 0.446 & $* * *$ & 0.026 & 0.446 & $* * *$ & 0.026 \\
\hline Stock market & -0.081 & & 0.056 & -0.081 & & 0.056 & -0.081 & & 0.056 \\
\hline Exporter & 0.003 & & 0.007 & 0.003 & & 0.007 & 0.003 & & 0.007 \\
\hline \multicolumn{10}{|l|}{ Firm size dummies ( $\mathrm{n}^{\circ}$ of workers) } \\
\hline From 10 to 49 & 0.025 & & 0.030 & 0.025 & & 0.030 & 0.025 & & 0.030 \\
\hline From 50 to 99 & 0.024 & & 0.030 & 0.023 & & 0.030 & 0.023 & & 0.030 \\
\hline From 100 to 199 & 0.044 & & 0.029 & 0.043 & & 0.029 & 0.043 & & 0.029 \\
\hline More than 200 & 0.036 & & 0.029 & 0.035 & & 0.029 & 0.035 & & 0.029 \\
\hline \multicolumn{10}{|l|}{ Region } \\
\hline Basque Country & 0.044 & $* * *$ & 0.014 & 0.045 & $* * *$ & 0.014 & 0.045 & $* * *$ & 0.015 \\
\hline Catalonia & 0.017 & $*$ & 0.009 & 0.017 & $*$ & 0.009 & 0.017 & $*$ & 0.010 \\
\hline Madrid & 0.039 & $* * *$ & 0.010 & 0.039 & $* * *$ & 0.010 & 0.040 & $* * *$ & 0.011 \\
\hline Valencia & 0.008 & & 0.013 & 0.008 & & 0.013 & 0.007 & & 0.013 \\
\hline High and medium-tech manufacturing & 0.014 & $*$ & 0.008 & 0.014 & $*$ & 0.008 & 0.014 & $*$ & 0.008 \\
\hline High-tech services & 0.038 & $* *$ & 0.016 & 0.039 & $* *$ & 0.016 & 0.039 & $* *$ & 0.016 \\
\hline Sigma of $\mathrm{u}$ & \multicolumn{3}{|c|}{0.177} & \multicolumn{3}{|c|}{0.177} & \multicolumn{3}{|c|}{0.177} \\
\hline Rho & \multicolumn{3}{|c|}{0.168} & \multicolumn{3}{|c|}{0.168} & \multicolumn{3}{|c|}{0.168} \\
\hline Number of observations & \multicolumn{3}{|c|}{22,137} & \multicolumn{3}{|c|}{22,137} & \multicolumn{3}{|c|}{22,137} \\
\hline
\end{tabular}

Std. E.: Estimated standard error. Coefficients significant at: 1\%***, 5\%**, 10\%*. All regressions include the constant. Dummy excluded for firms with fewer than 10 workers. 